\title{
Stress-Strain Relationship of Synthetic Fiber Reinforced Concrete Columns
}

\author{
Rosidawani ${ }^{1,2, *}$, Iswandi Imran ${ }^{1}$, Ivindra Pane ${ }^{1}$, and Saptahari Sugiri ${ }^{1}$ \\ ${ }^{1}$ Civil Engineering Department, Faculty of Civil and Environmental Engineering, Institut Teknologi \\ Bandung, 40116 Bandung, Indonesia \\ ${ }^{2}$ Civil Engineering Department, Faculty of Engineering, Universitas Sriwijaya, 30662 Palembang, \\ Indonesia
}

\begin{abstract}
Many empirical confinement models for normal and high strength concrete have been developed. Nevertheless, reported studies in the term of confinement of fiber reinforced concrete are limited. Whereas, the use of fiber reinforced concrete in structural elements has become the subject of the research and has indicated positive experiences. Since the stress-strain relationship of concrete in compression is required for analysis of structural members, the study of the stress-strain relationship for synthetic fiber reinforced concrete is substantial. The aim of the study is to examine the capabilities of the various models available in the literature to predict the actual experimental behavior of synthetic fiber reinforced highstrength concrete columns. The experimental data used are the results of the circular column specimens with the spiral spacing and the volume fraction of synthetic fiber as the test variables. The axial stress-strain curves from the tests are then compared with the various models of confinement from the literature. The performance index of each model is measured by using the coefficient of variation $(\mathrm{COV})$ concept of stress and strain behavior parameter. Among the confinement models, Cusson model shows the closest valid value of the coefficient of variation.
\end{abstract}

\section{Introduction}

Many empirical models of compression stress-strain relationship of normal and high strength concrete have been generated by many researchers [1-5]. However, those of models have limitation to fiber reinforced concrete, especially for synthetic fiber reinforced concrete (SNFRC). While, the development of research on synthetic fiber reinforced concrete has been expanded in structural applications. Moreover, this trend indicates positive experiences.

Experimentally compression stress-strain relationship of fiber reinforced concrete gave the significantly different result of the confinement effect from that of no fiber concrete. Consequently, it showed different trends of material behavior. The short and discrete fibers in the concrete mixture modify its typical brittle response to a significant increase in ductility about the no fiber concrete. Furthermore, a previous study has shown that SNFRC

* Corresponding author: rosidawani@gmail.com 
could improve the post-peak behavior, ductility, and energy dissipation ability of concrete elements under axial load [6]. It has proven that the combination of synthetic fibers and transverse steel confinement could reduce the amount of confining reinforcement and still behaved in ductile response [6].

The effect of fiber content investigation on the post-peak softening branch of the compressive stress-strain curve of steel fiber reinforced concrete (SFRC) found that an increase in the volumetric ratio of steel fibers leads to a relatively flatter post-peak softening branch of the curve [7]. Accordingly, the same trend was also found on SNFRC [6]. Also, this flatter post-peak softening branch behaved on the relatively same pattern due to the combination of discrete steel or synthetic fibers and reduced transverse steel confinement. Although few published research [8 - 10] have indicated positive field experiences with SNFRC, the ductile behavior of the fiber reinforced concrete which was being concerned with the research interest in the seismic performance of structural elements become an important issue.

Since the stress-strain relationship of concrete in compression is required for analysis of structural members, the study of stress-strain relationship for synthetic fiber reinforced concrete is substantial. Therefore, this paper presents the study, which examines the capabilities of the various models available in the literature to predict the actual experimental behavior of synthetic fiber reinforced high-strength concrete columns.

\section{Experimental and analytical program}

\subsection{Specimens}

Investigating the ability of the various models available in the literature to the relative performance of the number of column specimens based on the experimental study [6]. The test specimens used in the circular column specimens with the diameter of $135 \mathrm{~mm}$ and the cover of $10 \mathrm{~mm}$ contained six longitudinal bars of 10-mm diameter. Those specimens used spiral arrangement for the confinement, which consisted of 6-mm diameter ties spaced at either 30, 45 and $60 \mathrm{~mm}$. The specimen details and instrumentation are shown clearly in Fig. 1.

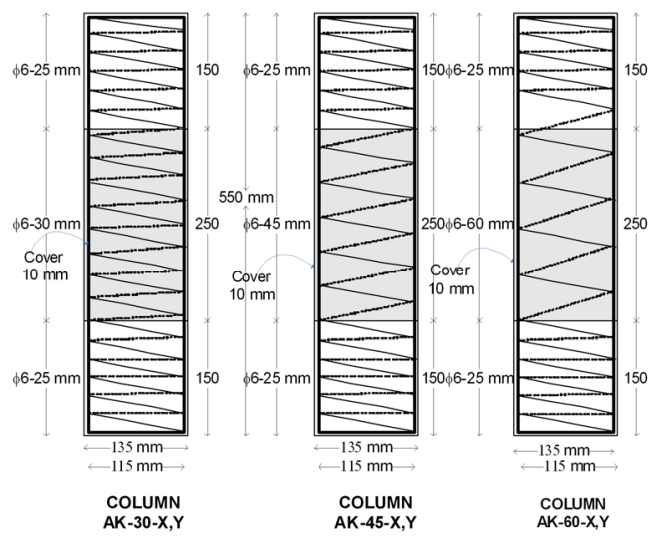

Fig. 1. Specimen details and instrumentation.

Furthermore, the concrete mixed contained 0.75 and 1.25 percent by weight of synthetic fiber and was cast with nominally $70 \mathrm{MPa}$ concrete. The strength of concrete for each series is respectively $64 \mathrm{MPa}, 65 \mathrm{MPa}$ and $63 \mathrm{MPa}$ for the $1.25 \%, 0.75 \%, 0 \%$ volume fraction of fiber inclusion in the concrete mixtures. 


\subsection{Confinement models}

Many researches proposed confinement model for high strength concrete columns, while a few for fiber reinforced concrete. Each model had various limitations. Since limited models available for fiber reinforced concrete, therefore, this investigation used both of fiber reinforced concrete [11,12] and no fiber concrete confinement [1-5] model. The aim is about examining the capabilities of the various models from the literature to predict the actual experimental behavior of synthetic fiber reinforced high-strength concrete columns. Table 1 illustrates those models.

Table 1. Confinement models

\begin{tabular}{|c|c|c|c|}
\hline \multirow[b]{2}{*}{ Model } & Ascending zone & Descending Zone & \multirow[b]{2}{*}{ Peak Stress } \\
\hline & $0<\varepsilon_{c}<\varepsilon_{c c}$ & $\varepsilon_{c}>\varepsilon_{c c}$ & \\
\hline Cusson [1] & $f=f^{\prime}{ }_{c c}\left[\frac{k \frac{\varepsilon_{c}}{\varepsilon_{c c}}}{k-1+\left(\frac{\varepsilon_{c}}{\varepsilon_{c c}}\right)^{k}}\right]$ & $\begin{array}{c}f=f^{\prime}{ }_{c c} \exp \\
{\left[k_{1}\left(\varepsilon_{c}-\varepsilon_{c c}\right)^{k_{2}}\right]}\end{array}$ & $\frac{f^{\prime}{ }_{c c}}{f^{\prime}{ }_{c}}=1+2.1\left(\frac{f_{l e}}{f_{c}^{\prime}}\right)^{0.7}$ \\
\hline Razvi [2] & $f=f_{c c}^{\prime}\left[\frac{k \frac{\varepsilon_{c}}{\varepsilon_{c c}}}{k-1+\left(\frac{\varepsilon_{c}}{\varepsilon_{c c}}\right)^{k}}\right]$ & $\begin{array}{c}f=f_{c c}^{\prime}-\left(\varepsilon_{c}-\varepsilon_{c c}\right) . \\
\frac{0.15 f^{\prime}{ }_{c c}}{\left(\varepsilon_{85 c c}-\varepsilon_{c c}\right)}\end{array}$ & ${f^{\prime}}_{c c}={f^{\prime}}_{c}+k_{1} f_{l e}$ \\
\hline Silva [3] & $f=f^{\prime}{ }_{c c}\left[\frac{k \frac{\varepsilon_{c}}{\varepsilon_{c c}}}{k-1+\left(\frac{\varepsilon_{c}}{\varepsilon_{c c}}\right)^{k}}\right]$ & $\begin{array}{c}f=f^{\prime}{ }_{c c} \exp \\
{\left[k_{1}\left(\varepsilon_{c}-\varepsilon_{c c}\right)^{k_{2}}\right]}\end{array}$ & ${f^{\prime}}_{c c}=f_{c o}+4.1 f_{l}$ \\
\hline Assa [4] & $f=f^{\prime}{ }_{c c} \frac{[\alpha x}{[1+(}$ & $\frac{\left.\beta-1) x^{2}\right]}{\left.2) x+\beta x^{2}\right]}$ & $\frac{f_{c c}^{\prime}}{f_{c}^{\prime}}=1+3.36 \frac{f_{l}}{f_{c}^{\prime}}$ \\
\hline $\mathrm{Li}[5]$ & $\begin{array}{c}0<\varepsilon_{c}<\varepsilon_{c o} \\
f=E_{c} \varepsilon_{c}+ \\
\frac{\left(f^{\prime}{ }_{c}-E_{c} \varepsilon_{c u}\right)}{\varepsilon_{c o}^{2}} \varepsilon_{c}^{2} \\
\varepsilon_{c o} \leq \varepsilon_{c} \leq \varepsilon_{c c} \\
f=f_{c c}^{\prime}-\frac{\left(f^{\prime}{ }_{c c}-f^{\prime}{ }_{c}\right)}{\left(\varepsilon_{c c}-\varepsilon_{c o}\right)^{2}} \\
x\left(\varepsilon_{c}-\varepsilon_{c c}\right)^{2}\end{array}$ & $\begin{array}{c}f=f_{c c}^{\prime}-\beta \frac{f^{\prime}{ }_{c c}}{\varepsilon_{c c}} \\
x\left(\varepsilon_{c}-\varepsilon_{c c}\right)\end{array}$ & 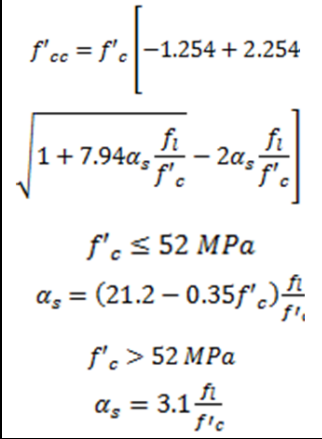 \\
\hline Mansur [11] & $\begin{array}{c}f_{c}=f_{c c} \\
{\left[\frac{\beta\left(\frac{\varepsilon_{c}}{\varepsilon_{c c}}\right)}{\beta-1+\left(\frac{\varepsilon_{c}}{\varepsilon_{c c}}\right)^{\beta}}\right]}\end{array}$ & $\begin{array}{c}f_{c}=f_{c c} \\
\left.\qquad \frac{k_{1} \beta\left(\frac{\varepsilon_{c}}{\varepsilon_{c c}}\right)}{k_{1} \beta-1+\left(\frac{\varepsilon_{c}}{\varepsilon_{c c}}\right)^{k_{2} \beta}}\right\rfloor\end{array}$ & $\frac{f_{c c}}{f_{o}}=1+0.6\left[\rho_{s} \frac{f_{y}}{f_{o}}\right]^{1.23}$ \\
\hline Campione [12] & $\frac{\sigma}{f^{\prime}{ }_{c}}=\frac{\beta\left(\varepsilon / \varepsilon_{0}\right)}{\beta-1+\left(\varepsilon / \varepsilon_{0}\right)^{\beta}}$ & $\begin{array}{c}\frac{\sigma}{f^{\prime}{ }_{c}}=\eta_{d} \exp \\
{\left[-k_{d}\left(\frac{\varepsilon}{\varepsilon_{0}}-x_{d}\right)^{2}\right]}\end{array}$ & $\frac{f^{\prime}{ }_{c c}}{f^{\prime}{ }_{c}}=1+2.1\left[k_{e} \frac{f_{l}}{f_{c}^{\prime}}\right]^{0.7}$ \\
\hline
\end{tabular}

Cusson [1] developed a confinement model which consists of two-part of stress-strain relationship for ascending and descending formula. This model was formulated based on 
the experimental study on 50 large-scale, under concentric loading of the concrete compressive strength of the specimens ranged from 60 to $120 \mathrm{MPa}$, while the ties used yield strength from 400 to $800 \mathrm{MPa}$.

Razvi [2] proposed the model of the ascending parabolic branch and descending branch up to $20 \%$ of the peak stress. The model was determined based on the nearly full-size column specimens of different shapes, sizes, reinforcement configuration, concrete strength, range 414 to $828 \mathrm{MPa}$ and tie yield strength range 400 to $1387 \mathrm{MPa}$.

Silva [3] developed two formulas for the confinement model which were based on Popovic's model (1973) for ascending model and Fafitis and Shah's model (1985) for descending branch. This model was predicted from 15 circular spirally confined (with yield strength 440 to $560 \mathrm{MPa}$ ) normal and high strength concrete columns (35.5 to $125.4 \mathrm{MPa})$.

Assa [4] proposed confinement model based on $22150 \times 300 \mathrm{~mm}$ concrete cylinders which were tested under monotonic concentric compression with 20 to $90 \mathrm{MPa}$ of the strength of concrete. The stress-strain behavior of concrete confined determined by the several types of reinforcement configurations.

Li et al. [5] developed the confinement model from the experimental results based on Murugama's model (1993). The experimental covered forty short column on cross-sectional shapes of cylindrical $(240 \mathrm{~mm})$ and square $(240 \times 240 \mathrm{~mm})$. The parameter of the tests consists of the strength of concrete (35.2 to $82.5 \mathrm{MPa})$, tie reinforcement yield strength (445 and $1318 \mathrm{MPa})$, spacing and volumetric ratio.

Mansur [11] proposed the confinement model from an experimental study for high strength plain and fiber concretes confined by transverse ties. This proposed model has reported well agreed with the stress-strain curves generated experimentally. It explained the confinement might also be provided by using a combination of transverse reinforcement and steel fibers. However, it was established the idea in term of incorporating the improvement in ductility due to the confinement in structural design. Furthermore, the experimental covered 180 specimens on cross-sectional shapes of prismatic consist of $75 \times 75 \times 150 \mathrm{~mm}, 100 \times 100 \times 200 \mathrm{~mm}, 125 \times 125 \times 300 \mathrm{~mm}$ dimensions with the strength range of $60-120 \mathrm{MPa}$ and transverse ties yield strength of $493 \mathrm{MPa}$.

Campione [12] developed the model to express the stress-strain relationship in compression of fiber reinforced concrete for both normal and high strength concrete, with and without conventional reinforcement. This model allows one to determine the maximum strength and strain capacity by determining the effective concrete core of the confining devices at rupture.

\section{Results and discussions}

This paper shows the relative performance of analytical models of stress-strain profile to the experimental results of the confined concrete column specimens. The combination of spirally confinement and volume fraction of synthetic fiber on twenty short column specimens observed experimentally [6]. Therefore, those parameters became the primary interest in predicting the performance of analytical confinement models to the experimental results.

The experimental results show that the ascending branches of the measured stress-strain relationships in all columns tests are almost linear, while the descending branches are flatter than those of no fiber concrete columns. Also, the descending branches of the columns with a closer spiral spacing and higher volume fraction of synthetic fibers are flatter than those with wider spacing and lower volume fraction of synthetic fiber. Seven stress-strain analytical models have been investigated their relative performance to the experimental stress-strain relationships of the specimens to propose the stress-strain models of this 
behavior. Still, these models apply to high strength concrete on circular sections, and three of models are generated from the fiber reinforced concrete.

The results show that the descending part of the curve of the synthetic fiber reinforced concrete columns are flatter and relatively maintain the stress less than $50 \%$ of the peak stress down. These behaviors are significantly different to no fiber concrete specimens. Therefore, the strain associated with the stress of $50 \%$ of the peak stress can be considered as an additional curve characterization of the descending portion of the stress-strain models. Consequently, the trend of the descending branch of the analytical models adopts the definition of the corresponding strain of $85 \%$ of peak stress and strain of $50 \%$ of peak stress to characterize the post-peak region. Fig. 2-Fig. 4 describe those analytical models.

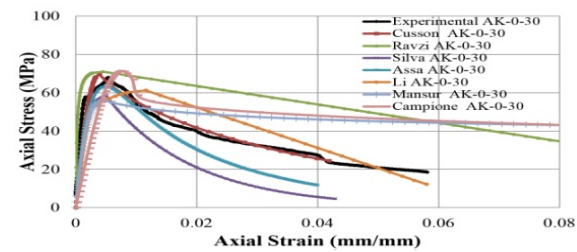

(a) Specimens AK-0-30

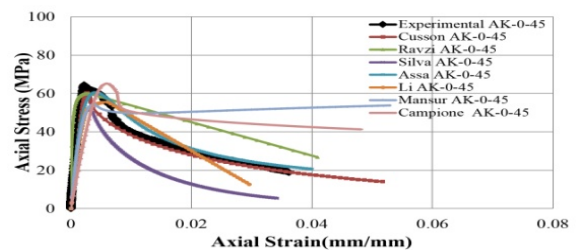

(b) Specimens AK-0-45

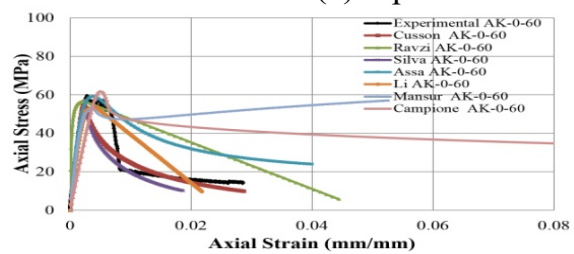

(c) Specimens AK-0-60

Fig. 2. Stress strain curve for specimens AK-0.

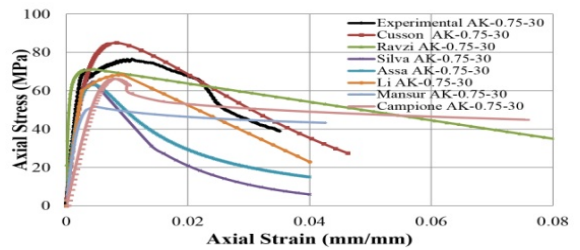

(a) Specimens AK-0.75-30

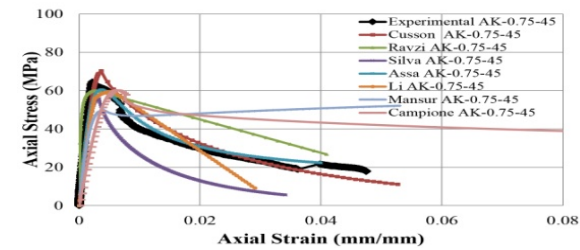

(b) Specimens AK-0.75-45

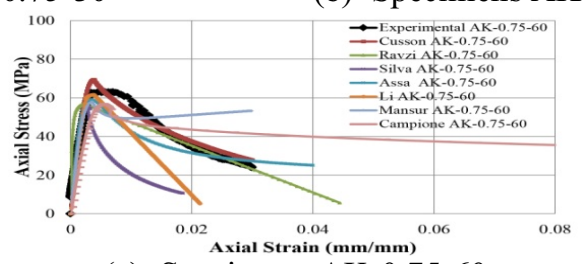

(c) Specimens AK-0.75-60

Fig. 3. Stress strain curve for specimens AK-0.75.

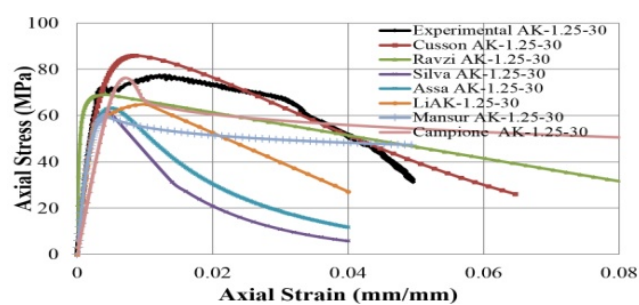

(a) Specimens AK-1.25-30

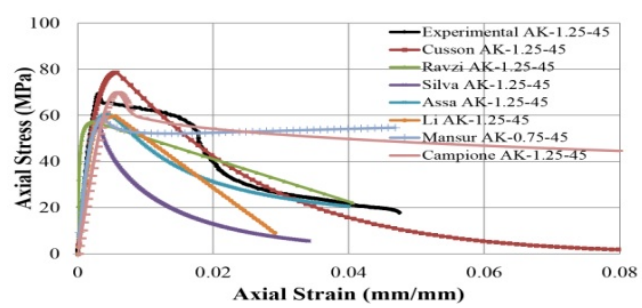

(b) Specimens AK-1.25-45 


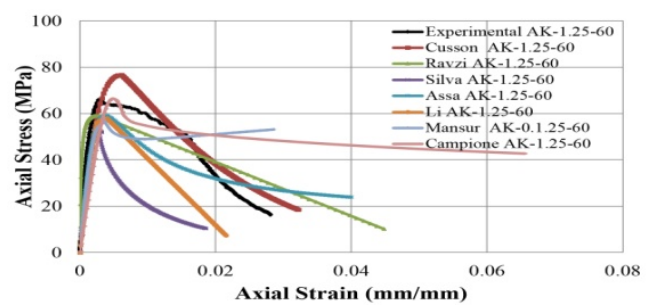

(c) Specimens AK-1.25-60

Fig. 4. Stress-strain curve for specimens AK-1.25.

The graphics in Fig. 2 to Fig. 4 describe the trends of the experimental results. Each picture shows the type of specimens with all confinement models applied to the experimental result. Cusson model shows the best-fitted graphic to the experimental result among others. The graphic trend for each of specimens tends to fit the experimental results. The descending curve retains the trend graph with the experimental data.

Ravzi and Li model give an overview chart opposites between the SNFRC and no fiber concrete specimens. This model describes the slightly underestimate trend chart on SNFRC. Conversely, no fiber concrete specimens illustrated an overestimate trend.

While Silva model provides the same underestimate trend for all the specimens, Assa model gives an illustration that varies in both types of material. Those models show that some are close enough to the experimental results while others remain to underestimate.

Mansur model, which was proposed for the steel fiber reinforced concrete column, shows an opposite trend in the chart between the SNFRC and no fiber concrete specimens. The model which was applied to the no fiber concrete provides an overestimate trend chart, nevertheless, an underestimate trend for the SNFRC.

Like Mansur, Campione model gives the same trend for an overview chart opposite between the SNFRC and no fiber concrete specimens. The overestimate trend charts are provided to the no fiber concrete, while the trend of SNFRC tends to approach with a slight underestimate value and different trend graphs.

Most of the models which are applied to either fiber reinforced concrete or no fiber concrete can define the peak stress $\left(f_{c c}\right)$ well. Meanwhile, the peak strain $\left(\varepsilon_{\mathrm{cc}}\right)$ value of all the models on all the specimens is varied. The significant differences are shown in the postpeak response of each model.

The capabilities of the stress-strain models of confined concrete columns to predict the actual behavior are determined by the parameters considered as the peak confined stress, $f_{c c}$, and the corresponded peak strain, $\varepsilon_{\mathrm{cc}}$. Therefore, these parameters are used to show the relative performance of the various models using the ratios of the predicted parameters to the respective experimental parameters for all the specimens. The ratio of peak stress and the corresponded peak strain are shown in Table 2 - Table 5 respectively.

Table 2. Comparison of peak confined stress $f_{c c}$ of no fiber concrete

\begin{tabular}{|c|c|c|c|c|c|c|c|c|}
\hline \multirow{2}{*}{ Specimen } & \multirow{2}{*}{$f_{\text {cc exp }}$} & \multicolumn{7}{|c|}{$f_{\text {cc modelexp }}$} \\
\cline { 3 - 9 } & & Cusson & Ravzi & Silva & Assa & Li & Mansur & Campione \\
\hline$A K-0-30$ & 68.088 & 1.023 & 1.043 & 0.867 & 0.928 & 0.900 & 0.827 & 1.049 \\
\hline$A K-0-45$ & 64.547 & 0.935 & 0.928 & 0.816 & 0.937 & 0.861 & 0.844 & 1.011 \\
\hline AK-0-60 & 59.518 & 0.958 & 0.950 & 0.832 & 0.994 & 0.901 & 0.902 & 1.038 \\
\hline \multicolumn{2}{|c|}{ Average } & 0.972 & 0.974 & 0.838 & 0.953 & 0.887 & 0.858 & 1.032 \\
\hline \multicolumn{2}{|c|}{ COV } & $5 \%$ & $6 \%$ & $3 \%$ & $4 \%$ & $3 \%$ & $5 \%$ & $2 \%$ \\
\hline
\end{tabular}


Table 3. Comparison of peak confined stress $f_{c c}$ of SNFRC

\begin{tabular}{|c|c|c|c|c|c|c|c|c|}
\hline \multirow{2}{*}{ Specimen } & \multirow{2}{*}{$f_{\text {cc exp }}$} & \multicolumn{7}{|c|}{$f_{\text {cc modelexp }}$} \\
\cline { 3 - 9 } & & Cusson & Ravzi & Silva & Assa & Li & Mansur & Campione \\
\hline AK-0.75-30 & 76.47 & 1.113 & 0.932 & 0.846 & 0.827 & 0.894 & 0.677 & 0.866 \\
\hline AK-0.75-45 & 64.55 & 1.090 & 0.928 & 0.863 & 0.937 & 0.925 & 0.774 & 0.934 \\
\hline AK-0.75-60 & 63.31 & 1.097 & 0.893 & 0.871 & 0.934 & 0.974 & 0.916 & 0.898 \\
\hline AK-1.25-30 & 77.36 & 1.111 & 0.894 & 0.802 & 0.817 & 0.840 & 0.771 & 0.986 \\
\hline AK-1.25-45 & 69.49 & 1.132 & 0.822 & 0.802 & 0.871 & 0.859 & 0.847 & 1.007 \\
\hline AK-1.25-60 & 66.08 & 1.160 & 0.895 & 0.795 & 0.895 & 0.876 & 0.863 & 1.005 \\
\hline Average & 1.117 & 0.894 & 0.830 & 0.880 & 0.895 & 0.808 & 0.949 \\
\hline COV & $2 \%$ & $4 \%$ & $4 \%$ & $6 \%$ & $5 \%$ & $10 \%$ & $6 \%$ \\
\hline
\end{tabular}

Table 4. Comparison of peak confined strain $\varepsilon_{c c}$ of no fiber concrete

\begin{tabular}{|c|c|c|c|c|c|c|c|c|}
\hline \multirow{2}{*}{ Specimen } & \multirow{2}{*}{$\varepsilon_{\text {cc exp }}$} & \multicolumn{7}{|c|}{$\varepsilon_{\text {cc model/exp }}$} \\
\cline { 3 - 10 } & & Cusson & Ravzi & Silva & Assa & Li & Mansur & Campione \\
\hline AK-0-30 & 0.0054 & 0.722 & 0.841 & 0.910 & 0.924 & 2.143 & 0.824 & 1.367 \\
\hline AK-0-45 & 0.0022 & 1.219 & 1.337 & 1.586 & 1.923 & 2.788 & 1.799 & 2.695 \\
\hline AK-0-60 & 0.0028 & 0.908 & 0.853 & 1.052 & 1.351 & 1.521 & 1.296 & 1.786 \\
\hline \multicolumn{2}{|c|}{ Average } & 0.949 & 1.011 & 1.183 & 1.400 & 2.151 & 1.306 & 1.949 \\
\hline \multicolumn{2}{|c|}{ COV } & $26 \%$ & $28 \%$ & $30 \%$ & $36 \%$ & $29 \%$ & $37 \%$ & $35 \%$ \\
\hline
\end{tabular}

Table 5. Comparison of peak confined strain $\varepsilon_{c c}$ of SNFRC

\begin{tabular}{|c|c|c|c|c|c|c|c|c|}
\hline \multirow{2}{*}{ Specimen } & \multirow{2}{*}{$\varepsilon_{\text {cc exp }}$} & \multicolumn{7}{|c|}{$\varepsilon_{\text {cc modelexp }}$} \\
\cline { 3 - 9 } & & Cusson & Ravzi & Silva & Assa & Li & Mansur & Campione \\
\hline AK-0.75-30 & 0.011 & 0.764 & 0.423 & 0.405 & 0.406 & 0.855 & 0.425 & 0.713 \\
\hline AK-0.75-45 & 0.002 & 1.672 & 1.337 & 1.531 & 1.648 & 2.544 & 1.848 & 2.798 \\
\hline AK-0.75-60 & 0.005 & 0.831 & 0.516 & 0.617 & 0.731 & 0.824 & 0.769 & 1.246 \\
\hline AK-1.25-30 & 0.012 & 0.712 & 0.351 & 0.379 & 0.411 & 0.840 & 0.358 & 0.585 \\
\hline AK-1.25-45 & 0.003 & 1.908 & 0.832 & 1.113 & 1.398 & 1.849 & 1.279 & 1.897 \\
\hline AK-1.25-60 & 0.003 & 2.035 & 0.938 & 0.969 & 1.269 & 1.341 & 1.199 & 1.631 \\
\hline \multicolumn{2}{|c|}{ Average } & 1.320 & 0.733 & 0.836 & 0.977 & 1.376 & 0.980 & 1.479 \\
\hline \multicolumn{2}{|c|}{ COV } & $47 \%$ & $51 \%$ & $54 \%$ & $55 \%$ & $51 \%$ & $58 \%$ & $56 \%$ \\
\hline
\end{tabular}

Table 6. Comparison of strain at $85 \%$ of peak stress $\left(\varepsilon_{85 c c}\right)$ of no fiber concrete

\begin{tabular}{|c|c|c|c|c|c|c|c|c|}
\hline \multirow{2}{*}{ Specimen } & \multirow{2}{*}{$\varepsilon_{85 \text { cc exp }}$} & \multicolumn{7}{|c|}{$\varepsilon_{85 \text { cc model/exp }}$} \\
\cline { 3 - 10 } & & Cusson & Ravzi & Silva & Assa & Li & Mansur & Campione \\
\hline AK-0-30 & 0.009 & 0.864 & 2.879 & 0.783 & 1.031 & 2.200 & 3.086 & 1.105 \\
\hline AK-0-45 & 0.006 & 0.667 & 2.163 & 0.724 & 1.350 & 1.742 & 1.786 & 1.326 \\
\hline AK-0-60 & 0.007 & 0.443 & 1.388 & 0.514 & 1.125 & 1.101 & 1.273 & 0.946 \\
\hline \multicolumn{2}{|c|}{ Average } & 0.658 & 2.144 & 0.674 & 1.169 & 1.681 & 2.049 & 1.126 \\
\hline \multicolumn{2}{|c|}{ COV } & $32 \%$ & $35 \%$ & $21 \%$ & $14 \%$ & $33 \%$ & $46 \%$ & $17 \%$ \\
\hline
\end{tabular}


Table 7. Comparison of strain at $85 \%$ of peak stress $\left(\varepsilon_{85 c c}\right)$ of SNFRC

\begin{tabular}{|c|c|c|c|c|c|c|c|c|}
\hline \multirow{2}{*}{ Specimen } & \multirow{2}{*}{$\mathrm{e}_{85 \text { cc exp }}$} & \multicolumn{7}{|c|}{$\varepsilon_{85 \text { cc modelexp }}$} \\
\cline { 3 - 9 } & & Cusson & Ravzi & Silva & Assa & Li & Mansur & Campione \\
\hline AK-0.75-30 & 0.022 & 0.805 & 1.212 & 0.324 & 0.381 & 0.732 & 1.292 & 0.692 \\
\hline AK-0.75-45 & 0.006 & 0.975 & 2.164 & 0.689 & 1.198 & 1.589 & 0.000 & 2.151 \\
\hline AK-0.75-60 & 0.011 & 0.617 & 0.824 & 0.291 & 0.592 & 0.586 & 0.872 & 1.043 \\
\hline AK-1.25-30 & 0.032 & 0.719 & 0.826 & 0.234 & 0.252 & 0.566 & 0.766 & 0.362 \\
\hline AK-1.25-45 & 0.015 & 0.658 & 0.786 & 0.282 & 0.544 & 0.645 & 0.919 & 0.572 \\
\hline AK-1.25-60 & 0.012 & 0.851 & 0.887 & 0.290 & 0.647 & 0.597 & 0.816 & 0.640 \\
\hline Average & & 0.771 & 1.116 & 0.352 & 0.602 & 0.786 & 0.778 & 0.910 \\
\hline COV & & $17 \%$ & $48 \%$ & $48 \%$ & $54 \%$ & $51 \%$ & $55 \%$ & $71 \%$ \\
\hline
\end{tabular}

Table 8. Comparison of strain at $50 \%$ of peak stress $\left(\varepsilon_{50 c c}\right)$ of no fiber concrete

\begin{tabular}{|c|c|c|c|c|c|c|c|c|}
\hline \multirow{2}{*}{ Specimen } & \multirow{2}{*}{$\varepsilon_{50 \text { cc exp }}$} & \multicolumn{7}{|c|}{$\varepsilon_{50 \text { cc modelexp }}$} \\
\cline { 3 - 10 } & & Cusson & Ravzi & Silva & Assa & Li & Mansur & Campione \\
\hline AK-0-30 & 0.027 & 1 & 2.882 & 0.552 & 0.710 & 1.495 & 0 & 7.081 \\
\hline AK-0-45 & 0.017 & 1 & 2.155 & 0.576 & 1.220 & 1.231 & 0 & 8.845 \\
\hline AK-0-60 & 0.008 & 1.006 & 3.261 & 0.956 & 2.986 & 1.895 & 0 & 16.563 \\
\hline \multicolumn{2}{|c|}{ Average } & 1.002 & 2.766 & 0.695 & 1.639 & 1.540 & 0 & 10.830 \\
\hline \multicolumn{2}{|c|}{ COV } & $0.3 \%$ & $20 \%$ & $33 \%$ & $73 \%$ & $22 \%$ & N/A & $47 \%$ \\
\hline
\end{tabular}

Table 9. Comparison of strain at $50 \%$ of peak stress $\left(\varepsilon_{50 c c}\right)$ of SNFRC

\begin{tabular}{|c|c|c|c|c|c|c|c|c|}
\hline \multirow{2}{*}{ Specimen } & \multirow{2}{*}{$\varepsilon_{50 \text { cc exp }}$} & \multicolumn{7}{|c|}{$\varepsilon_{50 \text { cc modelexp }}$} \\
\cline { 3 - 9 } & & Cusson & Ravzi & Silva & Assa & Li & Mansur & Campione \\
\hline AK-0.75-30 & 0.035 & 1.000 & 2.244 & 0.399 & 0.522 & 0.924 & 0.000 & 8.704 \\
\hline AK-0.75-45 & 0.017 & 1.038 & 2.155 & 0.547 & 1.190 & 1.123 & 0.000 & 13.758 \\
\hline AK-0.75-60 & 0.023 & 0.986 & 1.127 & 0.308 & 1.035 & 0.586 & 0.000 & 9.046 \\
\hline AK-1.25-30 & 0.047 & 0.998 & 1.566 & 0.296 & 0.406 & 0.761 & 0.000 & 5.951 \\
\hline AK-1.25-45 & 0.022 & 1.000 & 0.443 & 0.443 & 0.983 & 0.907 & 0.000 & 10.414 \\
\hline AK-1.25-60 & 0.020 & 1.002 & 1.412 & 0.364 & 1.182 & 0.702 & 0.000 & 9.746 \\
\hline \multicolumn{2}{|c|}{ Average } & 1.004 & 1.491 & 0.393 & 0.886 & 0.834 & 0.000 & 9.603 \\
\hline \multicolumn{2}{|c|}{ COV } & $2 \%$ & $45 \%$ & $24 \%$ & $38 \%$ & $23 \%$ & N/A & $27 \%$ \\
\hline
\end{tabular}

Since the post-peak behavior of synthetic fiber reinforced concrete columns shows the significant difference compare to those of no fiber one, the parameters of the corresponding strain of the $85 \%\left(\varepsilon_{\mathrm{cc} 85}\right)$ and $50 \%\left(\varepsilon_{\mathrm{cc} 50}\right)$ of the peak stress $f_{c c}$ at the descending branch of the curve are also determined. Moreover, these parts become important to convince the aspect of ductility, and the post-peak failure of synthetic fiber reinforced concrete columns. The ratio of those two parameters is illustrated in Table 6 - Table 9.

Definition of the post-peak strain behavior corresponded to the $85 \%$ and $50 \%$ of the peak stress produces a significant difference among Cusson and other models. Moreover, Cusson model well defines the value of the post-peak strain with small variations on SNFRC and slightly underestimate to the no fiber concrete. Cusson model remarkably good provides the value of the post-peak strain on most of the SNFRC specimens with the COV 
value below $2 \%$ and $20 \%$ respectively for $\varepsilon_{50 \mathrm{cc}}$ and $\varepsilon_{85 \mathrm{cc}}$. Meanwhile, it produces a slight underestimate on the COV value for the no fiber specimens. Cusson model was derived from the steel fiber reinforced concrete specimen column. It shows the remarkably good value on both peak stress $\left(f_{c c}\right)$ of the SNFRC and no fiber concrete specimens with $2 \%$ and

$4.7 \%$ COV respectively for SNFRC and no fiber concrete. Peak strain values $\left(\varepsilon_{\mathrm{cc}}\right)$ are also well defined either on SNFRC or no fiber concrete specimens. Although the coefficient of variation produces quite large on both, Cusson model demonstrates the best value compared to the others. Cusson model also shows the best value in the post-peak conditions of the corresponding strain of the $85 \%$ and $50 \%$ peak stress $\left(\varepsilon_{85 \mathrm{cc}}\right.$ and $\left.\varepsilon_{50 \mathrm{cc}}\right)$. Still, the COV value of SNFRC specimens indicates better than that of no fiber concrete specimens.

Ravzi model produces the peak stress, which is relatively close to the experimental result on either SNFRC or no fiber concrete with a good variety. While at the peak and the post-peak strain, Ravzi gives different assessments on both types of specimens. The $\varepsilon_{\mathrm{cc}}$, $\varepsilon_{85 \mathrm{cc}}$, and $\varepsilon_{50 \mathrm{cc}}$ of the no fiber concrete specimens describe much better than those of SNFRC specimen. Overall, all variations in the models to the experimental results tend to produce the overestimate results.

Silva model well generates the peak stress on either SNFRC or no fiber concrete with the great variation (COV). Meanwhile, peak strain on both models represents the value of the test results with considerable variation. This model is not able to describe the post-peak strain value with the consistent pattern for the SNFRC and no fiber concrete as well.

Assa is a model which produces relatively good peak stress on either SNFRC or no fiber concrete with a good variation (COV). Conversely, the peak and the post-peak strain were not able to identify the experimental well, especially for SNFRC specimens.

Li model also produces close enough peak stress with a consistent COV on SNFRC and no fiber concrete specimens. However, peak and post-peak strain are described by the overestimate and underestimate with bad and inconsistent variation.

Mansur and Campione model well characterize the peak stress on the SNFRC and no fiber concrete specimen, while overestimate prediction belongs to the peak and post peak strain. Unfortunately, these two models failed in describing the post strain of $\varepsilon_{50 \mathrm{cc}}$.

From the seven confinement models which are used in this study, four models of those are equal to the comparison study made by [13], i.e. Ravzi, Silva, Assa and Li models. The same conclusions are obtained that almost all the models can correctly estimate the ascending part of the experimental stress-strain curve. However, the prediction of the descending part shows a wide variation. Also, no models which can accurately predict the complete behavior of high-strength concrete columns. However, those four models obtain better results since the coefficient of variation (COV) acquired is much smaller, especially in the term of strain. This study results, $14 \%-73 \%$ for COV of peak and post-peak strains ratio in predicting experimental values for all column specimens, while $51.31 \%-93.19 \%$ for those of Djauhari et. al.'s study [13].

\section{Conclusions}

i) The capabilities in predicting the actual compressive test behavior of the various confinement models to the relative performance of the spirally confined no fiber and the synthetic fiber reinforced high-strength concrete columns are defined well for the peak stress, otherwise for the peak and post peak strain.

ii) Most of the models of SNFRC and no fiber concrete correctly estimate the ascending part, while underestimate and overestimate the descending part of the experimental stress-strain curve. 
iii) The performance index of each model which was measured by using the coefficient of variation (COV) concept on some behavior parameters such as experimental peak confined strengths ${ }_{f c c}$, corresponding peak strain ${ }_{\varepsilon c c}$, post-peak strains ${ }_{\varepsilon 85 \mathrm{cc}}$, and $\varepsilon_{\varepsilon 50 \mathrm{cc}}$, from the experimental stress-strain curve show relatively wide variation.

(iv) The coefficient of variation (COV) of each behavior parameter in predicting experimental values for all specimens ranges from $0.3 \%$ to $73 \%$. The larger values of the COV show that the models are considered less accurate in predicting the value of the parameters. Among the confinement models, Cusson model shows the closest valid value of the coefficient of variation.

(v) Cussson model well predicted the descending part of the stress-strain curve of the fiber reinforced concrete, which is significantly different from the no fiber concrete.

\section{References}

[1] D. Cusson and P. Paultre, Stress-strain model for confined high-strength concrete, J. of Structural Engineering, 121(3), 468-477, (1995)

[2] S. Razvi and M.Saatcioglu, Confinement model for high-strength concrete, J. of Structural Engineering, 125(3), 281-289, (1999)

[3] P. Silva, Effect of concrete strength on axial load response of circular columns, Master Thesis, McGill University, Montreal, Canada, (2000)

[4] B. Assa, M. Nishiyama and F. Watanabe, New approach for modeling confined concrete I : circular columns, J. of Structural Engineering, 127 (7), 743-750, (2001)

[5] L. Bing, R. Park and H. Tanaka, Stress-strain behavior of high-strength concrete confined by ultra-high and normal-strength transverse reinforcement, ACI Structural J., 98(3), 395-406, (2001)

[6] Rosidawani, I. Imran, S. Sugiri and I. Pane, Behaviour of macro synthetic fiber reinforced concrete columns under concentric axial compression, Procedia Engineering, 125, 987-994, (2015)

[7] D.A. Fanella and A.E. Naaman, Stress-strain properties of fiber-reinforced mortar in compression, J. of The American Concrete Institute, 82(4), 475-483, (1985)

[8] A. Djumbong, D. Cusson and P. Paultre, Experimental study of influence of synthetic fibers on behavior of cylindrical high-strength concrete Columns, Proc.of the 37th Annual Conf. of the Canadian Society of Civil Engineering, QC, Canada, 10, (2008)

[9] H. Nguyen. Shear behavior of polypropylene fiber reinforced concrete beams, Master Thesis, University of Sherbrooke, Sherbrooke, QC, Canada, (2006)

[10] V. Chernov, H. Zlotnikov and M. Shandalov, Structural synthetic fiber-reinforced concrete-experience with marine applications, Concrete Int., 28(8), 56-61, (2006)

[11] M.A. Mansur, M.S. Chin, and T.H.Wee, Stress strain relationship of confined highstrength plain and fiber concrete, J. Of Materials in Civil Engineering, 9(4), 171 -179 (1997)

[12] G. Campione, The effects of fibers on the confinement models for concrete columns Canadian J. of Civil Engineering, 29(5), 742-750, (2002)

[13] Z. Djauhari, and I. Imran, Study of confinement models for high-strength concrete columns confined by high-strength steel, Proc.of the Int. Conf. on Earthquake Engineering and Disaster Mitigation, Jakarta, Indonesia, 518-527, (2008) 